\title{
The Effect of the Remplissage Procedure on Shoulder Stability and Range of Motion
}

\author{
An in Vitro Biomechanical Assessment
}

\author{
Ilia Elkinson, BHB, MBChB, FRACS, Joshua W. Giles, BESc, Kenneth J. Faber, MD, MHPE, FRCSC, Harm W. Boons, MD, \\ Louis M. Ferreira, BSc, BESc, James A. Johnson, PhD, and George S. Athwal, MD, FRCSC \\ Investigation performed at the H.U.L.C. Bioengineering Research Laboratory, University of Western Ontario, London, Ontario, Canada
}

\begin{abstract}
Background: The remplissage procedure may be performed as an adjunct to Bankart repair to treat recurrent glenohumeral dislocation associated with an engaging Hill-Sachs humeral head defect. The purpose of this in vitro biomechanical study was to examine the effects of the remplissage procedure on glenohumeral joint motion and stability.
\end{abstract}

Methods: Cadaveric shoulders $(n=8)$ were mounted on a biomechanical testing apparatus that applies simulated loads to the rotator cuff and the anterior, middle, and posterior heads of the deltoid muscle. Testing was performed with the shoulder intact, after creation of the Bankart lesion, and after repair of the Bankart lesion. In addition, testing was performed after Bankart repair with and without remplissage in shoulders with 15\% and 30\% Hill-Sachs defects. Shoulder motion and glenohumeral translation were recorded with an optical tracking system. Outcomes measured included stability (joint stiffness and defect engagement) and internal-external glenohumeral rotational motion in adduction and in $90^{\circ}$ of composite shoulder abduction.

Results: In specimens with a $15 \%$ Hill-Sachs defect, Bankart repair combined with remplissage resulted in a significant reduction in internal-external range of motion in adduction $\left(15.1^{\circ} \pm 11.1^{\circ}, p=0.039\right)$, but not in abduction $\left(7.7^{\circ} \pm 9.9, p=\right.$ 0.38), compared with the intact condition. In specimens with a $30 \%$ Hill-Sachs defect, repair that included remplissage also significantly reduced internal-external range of motion in adduction $\left(14.5^{\circ} \pm 11.3^{\circ}, p=0.049\right)$ but not in abduction $\left(6.2^{\circ} \pm\right.$ $\left.9.3^{\circ}, p=0.60\right)$. In specimens with a $15 \%$ Hill-Sachs defect, addition of remplissage significantly increased joint stiffness compared with isolated Bankart repair $(p=0.038$ ), with the stiffness trending toward surpassing the level in the intact condition $(p=0.060)$. In specimens with a $30 \%$ Hill-Sachs defect, addition of remplissage restored joint stiffness to approximately normal ( $p=0.41$ compared with the intact condition). All of the specimens with a $30 \%$ Hill-Sachs defect engaged and dislocated after Bankart repair alone. The addition of remplissage was effective in preventing engagement and dislocation in all specimens. None of the specimens with a 15\% Hill-Sachs defect engaged or dislocated after Bankart repair.

Conclusions: In this experimental model, addition of remplissage provided little additional benefit to a Bankart repair in specimens with a 15\% Hill-Sachs defect, and it also reduced specific shoulder motions. However, Bankart repair alone was ineffective in preventing engagement and recurrent dislocation in specimens with a $30 \%$ Hill-Sachs defect. The addition of remplissage to the Bankart repair in these specimens prevented engagement and enhanced stability, although at the expense of some reduction in shoulder motion.

Clinical Relevance: The remplissage procedure has substantial effects on shoulder stability and motion.

$\mathrm{O}$ sseous defects of the humeral head are commonly associated with traumatic anterior shoulder instability. The Hill-Sachs defect ${ }^{1}$ is an impression fracture of the posterosuperior humeral head that is present in $>80 \%$ of cases of recurrent glenohumeral instability ${ }^{2-5}$. A sizeable Hill-Sachs defect may result in a reduction of the rotational arc length of the

Disclosure: One or more of the authors received payments or services, either directly or indirectly (i.e., via his or her institution), from a third party in support of an aspect of this work. In addition, one or more of the authors, or his or her institution, has had a financial relationship, in the thirty-six months prior to submission of this work, with an entity in the biomedical arena that could be perceived to influence or have the potential to influence what is written in this work. No author has had any other relationships, or has engaged in any other activities, that could be perceived to influence or have the potential to influence what is written in this work. The complete Disclosures of Potential Conflicts of Interest submitted by authors are always provided with the online version of the article. 
The Journal of Bone \& Joint Surgery $\cdot$ Jbjs.org Volume 94-A · Number $11 \cdot$ June 6, 2012
The Effect of the Remplissage Procedure on Shoulder Stability and Range of Motion

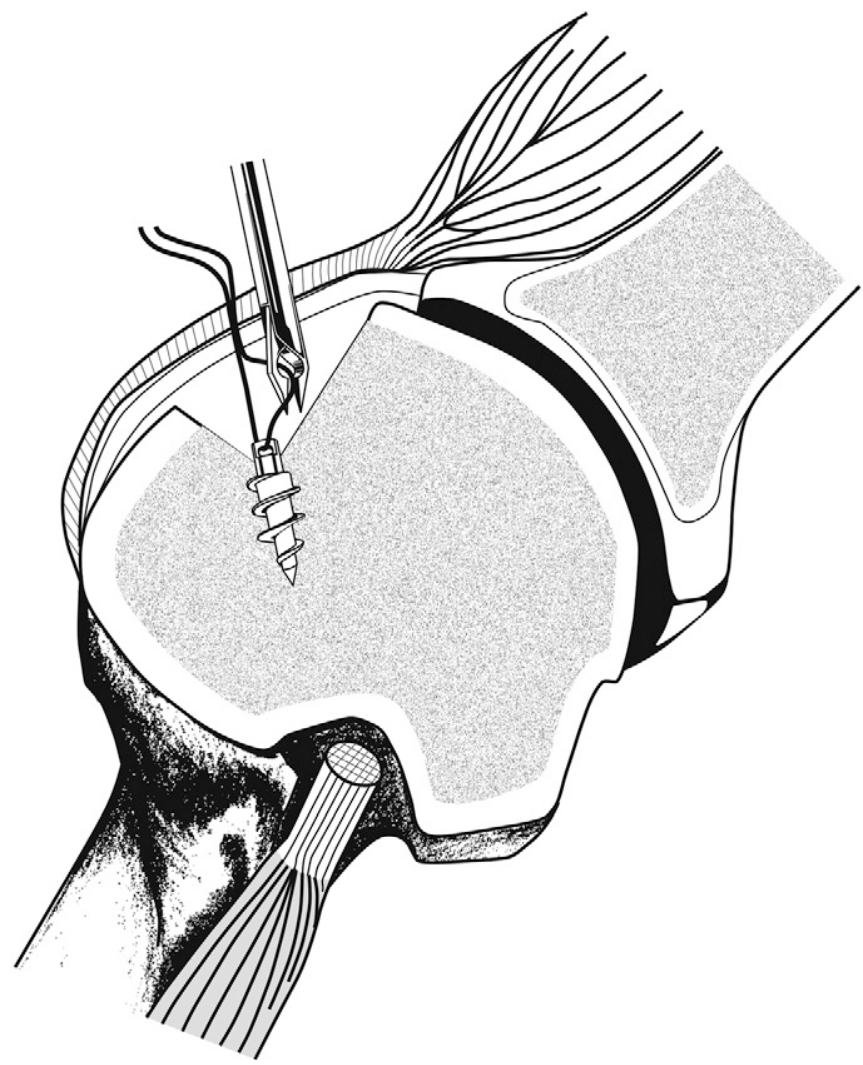

Fig. 1-A

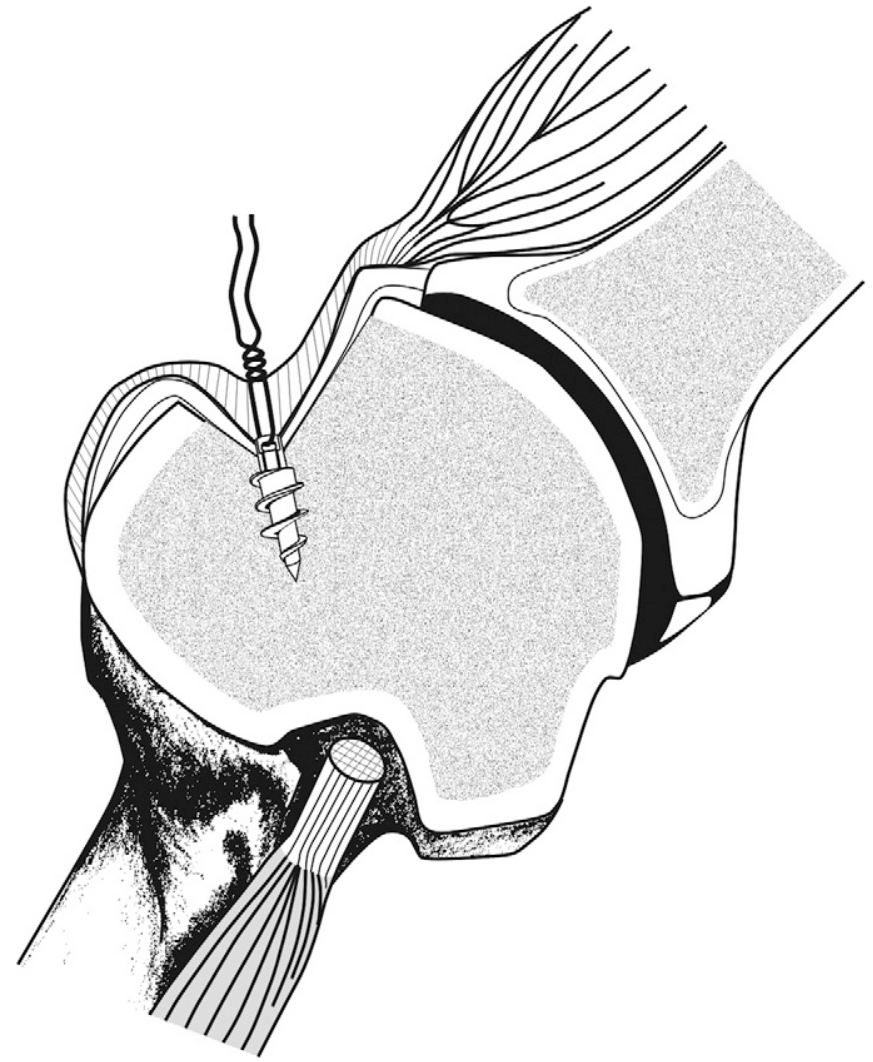

Fig. 1-B

Figs. 1-A and 1-B Remplissage is an arthroscopic procedure that insets the posterior shoulder capsule and infraspinatus tendon into the Hill-Sachs defect, converting the intra-articular location of the defect to an extra-articular one. Fig. 1-A The procedure is carried out by placing one or two suture anchors into the defect. A suture-passing device is then used to create mattress sutures through the posterior rotator cuff tendon and capsule. Fig. 1-B The sutures are then tied in the posterior subdeltoid space.

humeral head on the glenoid, which may lead to engagement of the defect on the anterior glenoid rim and resultant glenohumeral dislocation ${ }^{6}$. Arthroscopic repairs of Bankart lesions that do not address an engaging Hill-Sachs defect when one is present have been associated with higher failure rate ${ }^{2,5,7}$.

Several surgical procedures have been described for the management of engaging Hill-Sachs defects, including humeral rotational osteotomy, humeroplasty, reconstruction with osteochondral allograft, osteochondral transplantation, and partial or complete humeral head replacement ${ }^{4,8-18}$. In 2008, Purchase et al. described a technique of arthroscopic posterior capsulodesis and infraspinatus tenodesis into the Hill-Sachs defect to prevent engagement ${ }^{19}$. The authors termed the procedure "remplissage," which means "filling" in French. Insetting the posterior capsule and the infraspinatus tendon into the Hill-Sachs defect converts the intra-articular location of the defect to an extra-articular one. The remplissage procedure is performed in addition to a standard arthroscopic Bankart repair.

The remplissage procedure is typically performed arthroscopically by placing one or two suture anchors into the Hill-Sachs defect. An arthroscopic suture-passing device is then used to create mattress sutures through the posterior rotator cuff tendon and capsule, and these sutures are then tied in the subdeltoid space (Figs. 1-A and 1-B). Insertion of the soft tissue of the infraspinatus tendon and the posterior joint capsule fills the Hill-Sachs defect and also provides a bumper that is believed to prevent engagement. The remplissage procedure is used as an arthroscopic technique to address engaging Hill-Sachs defects, although to date few clinical outcome studies ${ }^{19,20}$ have been published in the peer-reviewed literature. We are unaware of any prior biomechanical studies of this procedure. The purpose of this in vitro biomechanical study was to assess the effects of the remplissage procedure on stability and motion in shoulders with Hill-Sachs defects of small and moderate size. We hypothesized that the remplissage procedure would effectively prevent engagement of the Hill-Sachs defect and would enhance shoulder stability, although at the expense of shoulder motion.

\section{Materials and Methods Specimen Preparation}

ight fresh-frozen cadaveric shoulders (mean donor age, seventy-three years; Crange, sixty-three to eight-seven years) were used in this in vitro biomechanical study. All specimens were examined and underwent computerized tomography (CT) to ensure that they were free of pathology. Digitization of the medial and lateral epicondyles, the humeral head, and multiple points on the glenoid and scapula was performed to create a clinically relevant coordinate system $^{21}$. The specimens were mounted on a custom dynamic shoulder testing 
The Journal of Bone \& Joint Surgery $\cdot$ JBjS. Org Volume 94-A · Number $11 \cdot$ June 6, 2012

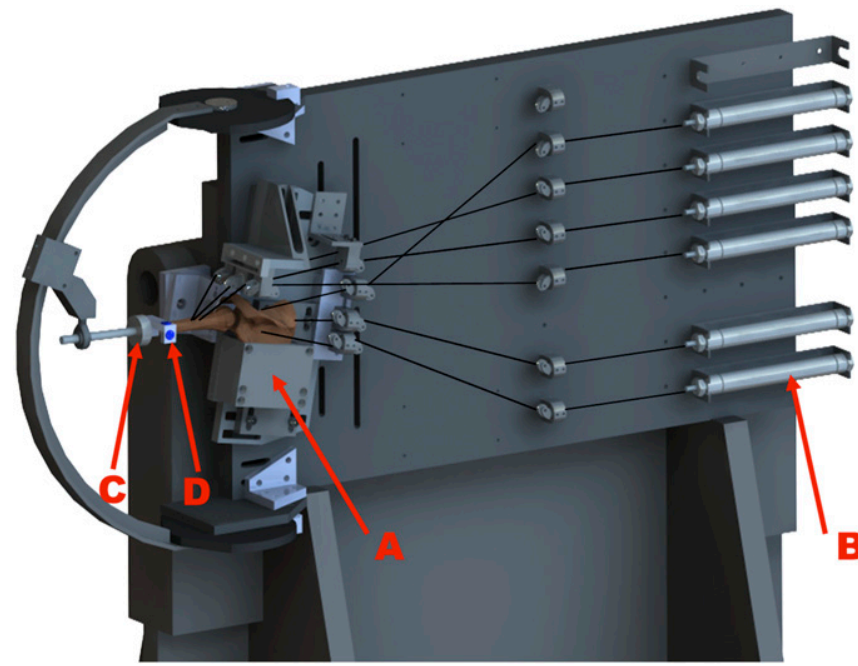

Fig. 2

A custom dynamic testing system that simulated unconstrained glenohumeral motion was used to study the effects of the remplissage procedure on Hill-Sachs defects of small (15\%) and moderate (30\%) size. The scapular holder (A) had the ability to rotate from neutral to $30^{\circ}$ of abduction to simulate composite shoulder girdle abduction. The testing platform allowed actuation of the individual rotator cuff muscles and the anterior, middle, and posterior heads of the deltoid. Muscle actuation was accomplished by suturing the individual tendons at the musculotendinous junctions, and routing the sutures through alignment guides replicated the physiologic lines of action. The individual sutures were then attached to computer-controlled pneumatic actuators (B) that applied physiologic loads. An instrumented intramedullary humeral rod equipped with a six-degree-of-freedom load cell measured joint loads and torques (C). Additionally, to accurately monitor continuous shoulder motion and instantaneous glenohumeral relationships, optical markers were attached to the scapula and the humerus (D).

system (Fig. 2) that simulated unconstrained glenohumeral motion ${ }^{22-25}$. The simulator allowed actuation of the individual rotator cuff muscles and the anterior, middle, and posterior heads of the deltoid muscle (see Appendix). To accurately assess continuous shoulder motion and instantaneous glenohumeral spatial relationships, optical markers (Optotrak Certus; Northern Digital, Waterloo, Ontario, Canada) were attached to the scapula and the humerus. The output data from the optical markers were captured in real time.

Typically, the remplissage procedure is performed using an arthroscopic approach. However, the steps necessary to measure and create the Hill-Sachs defects would have been technically challenging to perform through an arthroscope, so an extended osteotomy of the lesser tuberosity of the humerus was used to access the glenohumeral joint. The osteotomy was fixed with two bicortical bolt-and-nut constructs to allow repeated exposure of the joint without compromising fixation. To assess the effect of the osteotomy, the shoulder was retested after the osteotomy and compared with the intact state.

\section{Dependent Variables}

The testing protocol was designed to study the effects of the remplissage procedure on shoulder stability and motion in shoulders with Hill-Sachs defects of small $(15 \%)$ and moderate (30\%) size. Testing was performed in the intact shoulder, after osteotomy and repair of the lesser tuberosity, after creation of an isolated Bankart lesion, and after repair of the Bankart lesion. In addition, testing was performed after Bankart repair with and without remplissage in shoulders with accompanying Hill-Sachs defects spanning $15 \%$ and $30 \%$ of the diameter of the humeral head.
The Effect of the Remplissage Procedure on Shoulder Stability and Range of Motion
The Hill-Sachs defects were created in the posterosuperior region of the humeral head utilizing the scientific methods described by Sekiya et al. ${ }^{16}$ and Yamamoto et $\mathrm{al}^{26}$. The specimens were placed in $90^{\circ}$ of combined abduction $\left(30^{\circ}\right.$ of scapular abduction and $60^{\circ}$ of glenohumeral abduction) and $60^{\circ}$ of external rotation. With the glenohumeral joint in this position, a line was drawn on the humeral head parallel to the anteroinferior glenoid rim. This line represented the angular orientation of the Hill-Sachs defect that would plausibly result from a traumatic anterior glenohumeral dislocation with the shoulder girdle in $90^{\circ}$ of combined abduction and $60^{\circ}$ of external rotation ${ }^{16,26}$. Once the angular orientation of the defect was determined, the humeral head diameter was measured with a digital caliper. Defects of $15 \%$ and $30 \%$ were outlined on the humeral head (Fig. 3) and created sequentially with a microsagittal saw ${ }^{16}$.

During protocol development, we examined the scientific methods of Sekiya et al. ${ }^{16}$ and Yamamoto et al. ${ }^{26}$ to assist with creation of the Hill-Sachs defects. Although each clinical Hill-Sachs defect differs slightly in dimensions and orientation, we sought to develop a model that could be easily reproduced from specimen to specimen and that could be replicated by other researchers. As Hill-Sachs defects have been described as being triangular, we defined the posterior articular margin of the humeral head-neck junction as being the base of the defect. A right-angle triangle was then used to prescribe the depth of the defect (valley) where the suture anchors would be placed (Fig. 4). This right angle

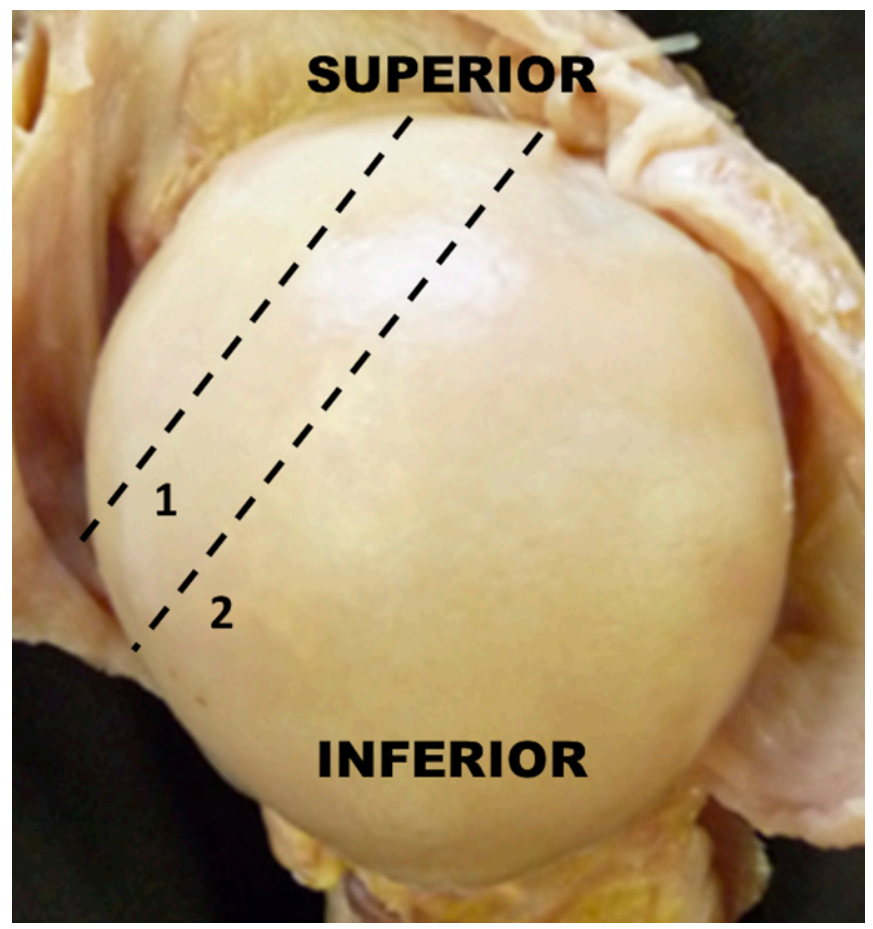

Fig. 3

Hill-Sachs defects were created in the posterosuperior region of the humeral head according to the method described by Sekiya et al. ${ }^{16}$. The specimens were placed in $90^{\circ}$ of composite abduction and $60^{\circ}$ of glenohumeral external rotation. With the glenohumeral joint in this position, a line was drawn on the humeral head parallel to the anteroinferior glenoid rim. This line represented the angular orientation of the Hill-Sachs defect that would have plausibly resulted from a traumatic anterior dislocation with the shoulder girdle in this position of abduction and external rotation. Once the angular orientation of the defect was determined, the humeral head diameter was measured with a digital caliper. Defects that encompassed $15 \%$ (1) and 30\% (2) of the humeral head diameter were then marked on the posterosuperior aspect of the humeral head. 


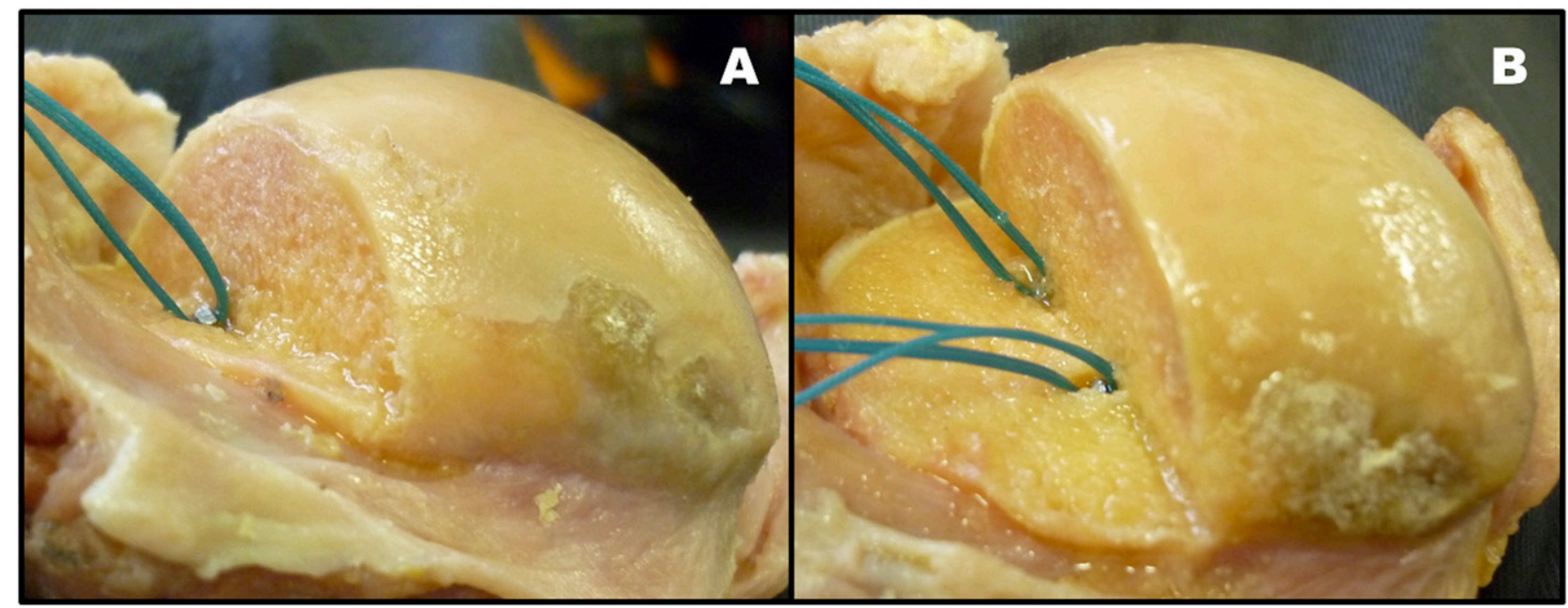

Fig. 4

Fig. 4-A The remplissage procedure (posterior capsulodesis and infraspinatus tenodesis) for the $15 \%$ Hill-Sachs defect was conducted by placing a double-loaded 5-mm suture anchor into the center of the valley defect. Fig. 4-B The $30 \%$ defect was repaired by placing two double-loaded suture anchors into the valley of the defect. The superior anchor was placed at the junction of the upper and the middle third of the defect, and the inferior anchor was placed at the junction of the middle and the lower third. The accompanying sutures were passed through the posterior capsule and the rotator cuff using a horizontal mattress technique and then tied.

allowed the definition of a plane that was perpendicular to the base and represented the medial margin of the Hill-Sachs defect. Usage of the head-neck junction as the base landmark created a consistent, albeit "worst case," scenario for defining the Hill-Sachs defects.

The remplissage procedure for the $15 \%$ defect was performed by placing one double-loaded 5-mm suture anchor (Super Revo; ConMed Linvatec, Largo, Florida) into the valley of the defect (Fig. 4-A) as described by Purchase et al. ${ }^{19}$. The accompanying sutures were passed through the posterior capsule and infraspinatus using a straight needle, resulting in a horizontal mattress stitch that was then tied in the subdeltoid space. The $30 \%$ defect was repaired with two double-loaded suture anchors similarly placed into the defect (Fig. 4-B).

\section{Experimental Protocol}

The joint was vented to atmospheric pressure and kept moist with saline solution. After osteotomy of the lesser tuberosity, a scalpel was used to separate the anteroinferior labrum from the glenoid to create a Bankart lesion. Additionally, a capsular injury was created by dividing the anteroinferior capsule horizontally. To ensure that the glenohumeral joint was unstable, it was forcibly dislocated in the anteroinferior direction, propagating the capsulolabral injury. The Bankart repair was conducted with two suture anchors place at the 4:30 and 6:00 positions on the glenoid. The sutures were passed through the labrum using a horizontal mattress technique and were then tied. The horizontal capsulotomy was repaired with two side-to-side sutures.

Glenohumeral joint stability was quantified in terms of stiffness. The stiffness was calculated (in $\mathrm{N} / \mathrm{mm}$ ) by applying an anteriorly directed quasistatic $80-\mathrm{N}$ force ${ }^{27-32}$ to the humeral head while measuring head translation on the glenoid with the optical motion-capture system. This was continued until glenohumeral dislocation occurred or until a soft-tissue end point was reached without dislocation (stability). The force was applied through a uniaxial load cell (Model 34 Precision Miniature; Honeywell, Golden Valley, Minnesota). The aforementioned anteriorly directed force was used to calculate stiffness only; it was not used in the determination of engagement. Engagement was assessed by placing the shoulder into abduction and external rotation and then gradually moving the arm into extension, allowing the humeral head to rotate. Engagement occurred when the humeral head rotated externally, which allowed the medial margin of the Hill-Sachs defect to slot into the anteroinferior glenoid rim. Engagement of the defect was defined as a sudden and abrupt medial displacement of the humeral head rotational center, as recorded by the optical tracking system and confirmed visually by two observers.

\section{Data and Statistical Analysis}

The data obtained for each testing condition included glenohumeral motion, the occurrence of engagement, the force required to dislocate the humeral head, joint translation, and joint stiffness. Glenohumeral motion was measured in adduction, abduction, and extension. In adduction, internal-external rotational motion was recorded. In $90^{\circ}$ of composite shoulder abduction, two motions were measured: (1) internal-external rotation in the scapular plane, and (2) horizontal extension of the shoulder posteriorly with the humerus in $60^{\circ}$ of external rotation. The extension motion in external rotation was selected because it replicates the position of patient apprehension and is the provocative position for Hill-Sachs defect engagement. To ensure consistency, the end points of the range of motion were determined by rotating the humerus with a predefined torque of $0.65 \mathrm{Nm}$. This torque value was determined, as an average of several trials, by one author (G.S.A.) who manually rotated a pilot test specimen to the extremes of motion and stopped when resistance consistent with that in a clinical examination was encountered. Range of motion values were obtained with use of the motion capture system.

Statistical analysis was performed with one-way and two-way repeatedmeasures analysis of variance (ANOVA). A p value of $<0.05$ was considered significant.

\section{Source of Funding}

This research was supported by a grant from the Academic Medical Organization of Southwestern Ontario, which provided salary support for one author (G.S.A.). Two investigators received funding from the National Science and Engineering Research Council (J.W.G., J.A.J.). Additionally, suture anchors were donated by ConMed Linvatec. That company or the granting agency had no influence over the design or conduct of the study or the analysis or interpretation of the study data.

\section{Results}

To significant differences in shoulder motion or glenohumeral 1 joint stiffness were observed between the intact specimens and the specimens that had undergone lesser tuberosity osteotomy $(\mathrm{p}>0.05)$.

\section{Bankart Lesion without Hill-Sachs Defect}

In adduction, creation of the Bankart lesion did not result in a significant change (mean and standard deviation, $3.3^{\circ} \pm 5.9^{\circ} ; \mathrm{p}=$ 
The Journal of Bone \& Joint Surgery · Jbjs.org Volume 94-A · Number 11 - June 6, 2012
The Effect of the Remplissage Procedure on Shoulder Stability and Range of Motion
0.460) in internal-external rotation range of motion compared with the intact condition. However, the Bankart and capsular repair after dislocation did result in a significant reduction in internal-external rotation range of motion compared with the intact condition $\left(13.4^{\circ} \pm 11.1^{\circ}, \mathrm{p}=0.033\right)$ and compared with the Bankart lesion condition $\left(16.8^{\circ} \pm 9.6^{\circ}, \mathrm{p}=0.005\right)$.

In abduction, the Bankart lesion also did not significantly increase internal-external rotation range of motion $\left(3.2^{\circ} \pm\right.$ $\left.6.8^{\circ}, \mathrm{p}=0.460\right)$. However, the Bankart lesion with a capsular repair did significantly decrease internal-external rotation range of motion compared with the Bankart lesion condition $\left(14.5^{\circ} \pm 11.9^{\circ}, \mathrm{p}=0.031\right)$. The Bankart lesion with a capsular repair also trended toward decreased rotation compared with the intact condition $\left(11.4^{\circ} \pm 12.4^{\circ}, \mathrm{p}=0.110\right)$, although this difference did not reach significance.

In abduction and external rotation, creation of the Bankart lesion trended toward increased extension range of motion $\left(10.8^{\circ} \pm 10.5^{\circ}, \mathrm{p}=0.064\right)$. However, the Bankart lesion and capsular repair did significantly reduce extension range of motion in the abducted and externally rotated position by $20.0^{\circ} \pm 12.3^{\circ}(\mathrm{p}=0.007)$ compared with the Bankart lesion condition.

\section{Small Hill-Sachs Defect}

After Bankart lesion repair alone, specimens with a 15\% HillSachs defect did not engage the glenoid rim in any testing position. Adding the remplissage procedure to the standard Bankart repair significantly reduced internal-external range of motion in adduction by $15.1^{\circ} \pm 11.1^{\circ}(\mathrm{p}=0.039)$ compared with the intact condition and by $13.7^{\circ} \pm 9.8^{\circ}(\mathrm{p}=0.034)$ compared with Bankart repair alone (Fig. 5-A). In abduction, however, the decrease in internal-external rotation motion when the remplissage procedure was added was not significant compared with the intact condition $\left(7.7^{\circ} \pm 9.9^{\circ}, \mathrm{p}=0.380\right)$ or compared with Bankart repair alone $\left(5.7^{\circ} \pm 11.6^{\circ}, \mathrm{p}=1.000\right)$ (Fig. 5-B). However, addition of the remplissage procedure to the Bankart repair resulted in a significant reduction in extension range of motion compared with Bankart repair alone $\left(22.0^{\circ} \pm\right.$ $15.3^{\circ}, \mathrm{p}=0.029$ ) (Fig. 5-C).

Addition of the remplissage procedure to the Bankart repair resulted in a significant increase in mean glenohumeral joint stiffness $(4.7 \pm 4.0 \mathrm{~N} / \mathrm{mm}, \mathrm{p}=0.038)$. The remplissage procedure also tended to increase joint stiffness compared with the intact condition $(4.1 \pm 3.9 \mathrm{~N} / \mathrm{mm})$, but this difference did not reach significance $(\mathrm{p}=0.060)$ (Fig. 6).

\section{Moderate Hill-Sachs Defect}

None of the eight specimens with a 30\% Hill-Sachs defect engaged in adduction after Bankart lesion repair alone. However, they all engaged and dislocated in abduction with external rotation. Remplissage was effective in preventing defect engagement in abduction with external rotation in all eight specimens. In four specimens, the soft-tissue bumper created by insetting the capsule and infraspinatus tendon into the defect impinged on the posterior rim of the glenoid, which resulted in pivoting of the humeral head and distraction of the glenohumeral joint.
In adduction (Fig. 5-A), addition of the remplissage procedure to the standard Bankart repair resulted in a significant reduction in internal-external rotation range of motion compared with Bankart repair alone $\left(19.5^{\circ} \pm 7.8^{\circ}, \mathrm{p}=0.001\right)$. Remplissage also resulted in a statistically significant reduction in internal-external rotation motion compared with the intact condition $\left(14.5^{\circ} \pm 11.3^{\circ}, \mathrm{p}=0.049\right)$. In abduction (Fig. 5 -B), addition of remplissage significantly reduced internalexternal rotation motion by a mean of $12.2^{\circ} \pm 8.6^{\circ}(\mathrm{p}=0.030)$ compared with Bankart repair alone. However, the reduction in internal-external rotation motion in abduction after remplissage was not significant compared with the intact condition $\left(6.2^{\circ} \pm 9.3^{\circ}, \mathrm{p}=0.60\right)$. A trend toward decreased extension range of motion $\left(10.6^{\circ} \pm 9.1^{\circ}, \mathrm{p}=0.080\right)$ was observed with addition of the remplissage procedure compared with the Bankart repair alone, although the decrease in extension was not significant compared with the intact condition $\left(6.0^{\circ} \pm 9.5^{\circ}, \mathrm{p}=0.700\right)$ (Fig. 5-C).

The addition of remplissage to the Bankart repair increased joint stiffness significantly $(3.9 \pm 3.2 \mathrm{~N} / \mathrm{mm}, \mathrm{p}=0.030)$. The added stabilization of the remplissage procedure brought the joint stiffness value to near the intact level, with no significant difference from the intact condition $(2.6 \pm 4.4 \mathrm{~N} / \mathrm{mm}$, $\mathrm{p}=0.410)$ (Fig. 6).

\section{Discussion}

7 he management of Hill-Sachs defects remains controversial. Current understanding of the factors that result in clinically important Hill-Sachs defects is poor. The critical width, angular orientation, and depth remain unknown. Sekiya et al. ${ }^{16}$ examined various sizes of Hill-Sachs defects in a cadaveric study and reported that shoulder position, defect size, and defect orientation were all important factors. In 2007, Yamamoto et al. ${ }^{26}$ introduced the concept of the glenoid track. In their cadaveric study, they determined that the medial margin of the glenoid track was located an average of $18.4 \pm 2.5 \mathrm{~mm}$ medial to the posterior edge of the rotator cuff footprint. Yamamoto et al. ${ }^{26}$ stated that the orientation and width of the Hill-Sachs defect were more important than the depth and length. Consequently, in their glenoid track theory, they did not address the depth of the Hill-Sachs defect. On the basis of the results of the present experiments, we agree with the conclusions of Yamamoto et al. ${ }^{26}$ that width and orientation are more important than depth. We observed that when a Hill-Sachs defect engages the anterior glenoid rim and results in medialization of the humeral head and glenohumeral dislocation, the depth to which it medializes is irrelevant, as the humeral head has already dislocated.

Remplissage has been described as an adjunct to a standard Bankart repair for the management of engaging HillSachs humeral head defects ${ }^{19}$. The technique is promising because it provides the surgeon with an all-arthroscopic solution to address capsulolabral pathology and an engaging HillSachs defect, whereas most of the currently available treatment options for Hill-Sachs defects involve open surgery. Other potential advantages of the remplissage procedure include the 


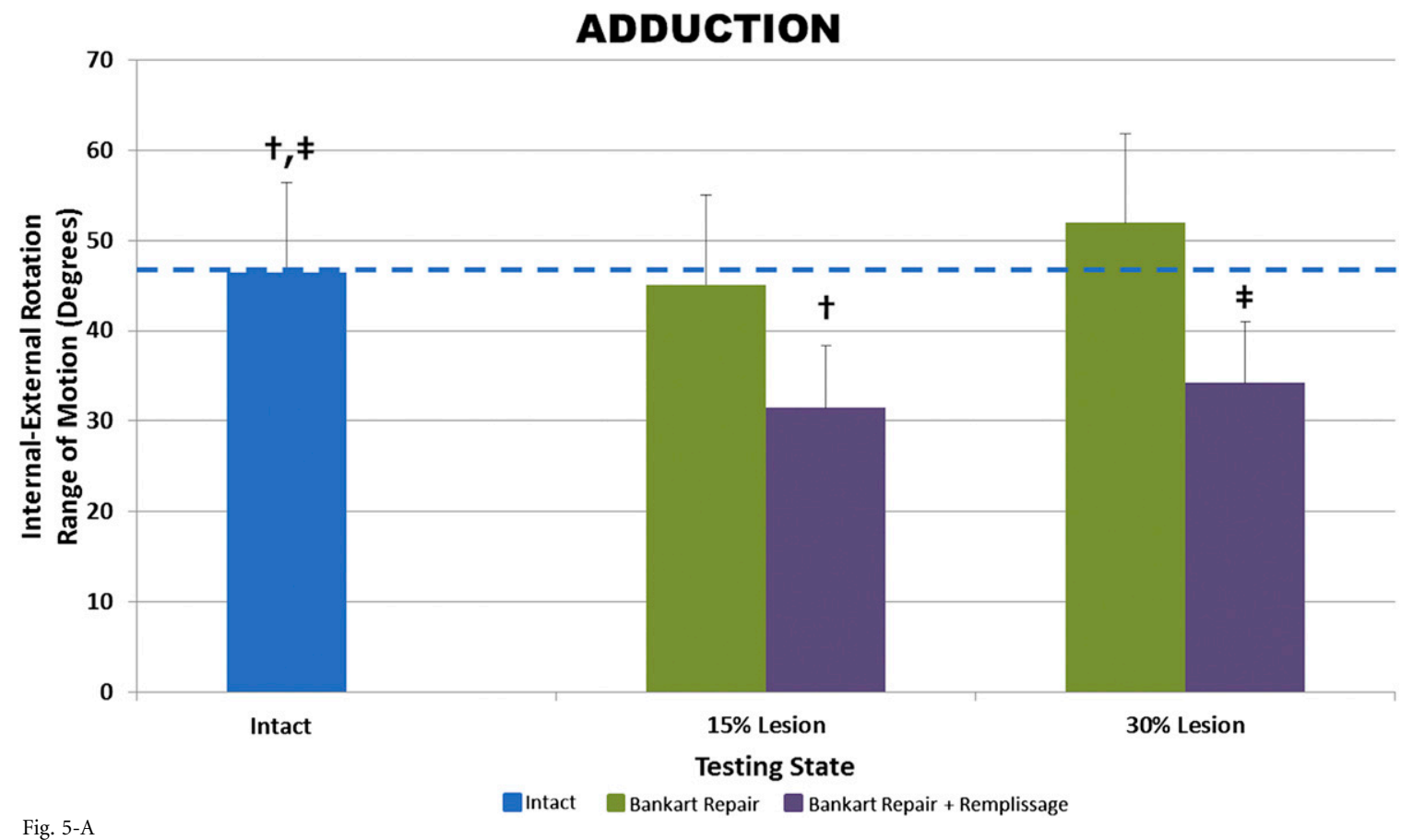

Fig. 5-A

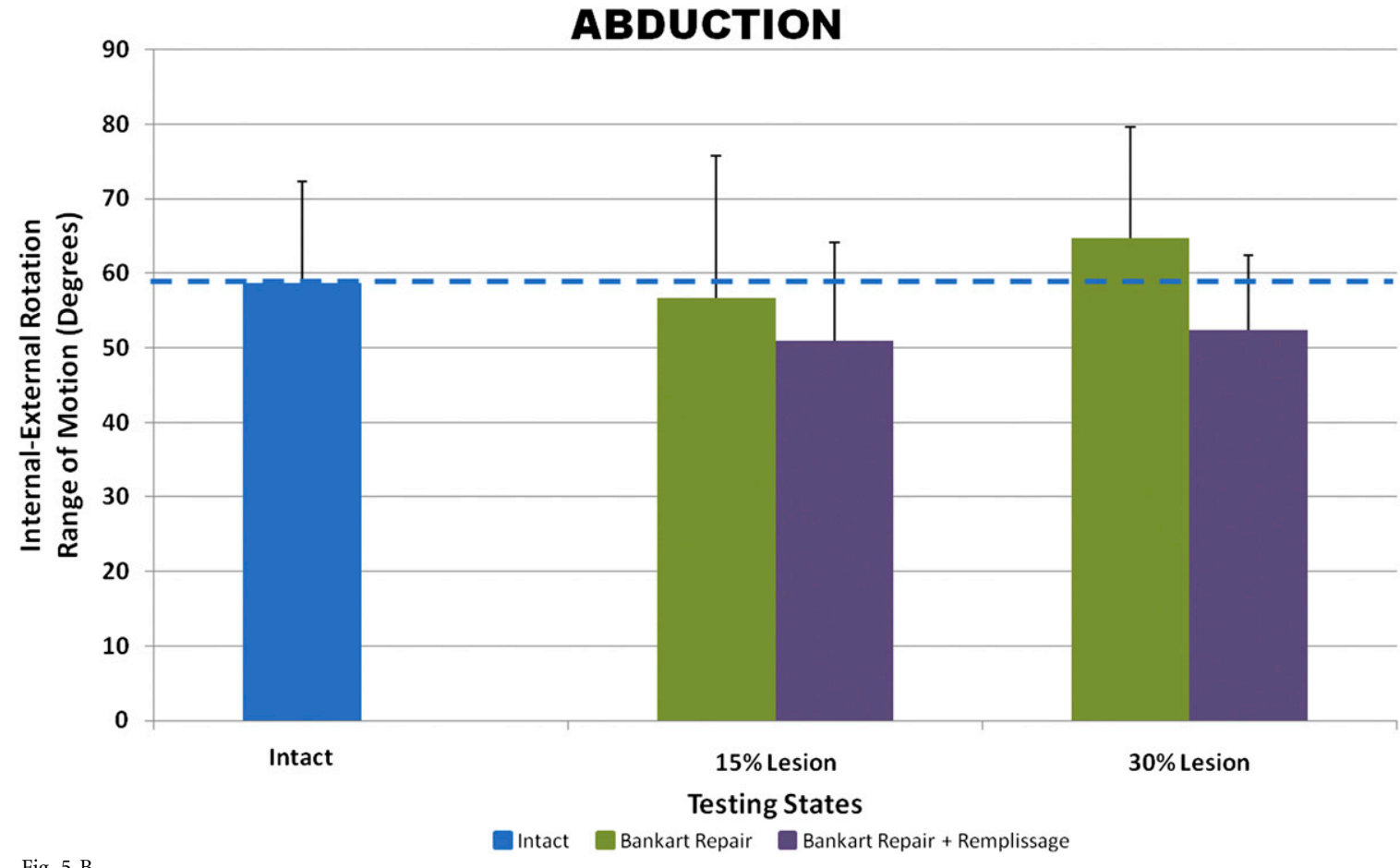

Figs. 5-A, 5-B, and 5-C Range of motion results for the intact condition and for $15 \%$ and $30 \%$ Hill-Sachs defects with and without remplissage; $\dagger$ and $\ddagger$ indicate pairwise comparisons with significant differences. Figs. 5-A and 5-B Internal-external glenohumeral range of motion in adduction and in abduction.

use of local tissue with no additional graft material or metallic implants apart from the suture anchors. Furthermore, there is no danger of disease transmission or graft resorption, which can occur with allograft reconstruction.
Unfortunately, there are few clinical studies in the peerreviewed literature that critically describe the outcomes of the remplissage procedure. Several technical reports describe good short-term outcomes with few complications. In 2008, Deutsch 
The Journal of Bone \& Joint Surgery $\cdot$ JbJs.org Volume 94-A · Number 11 · June 6, 2012

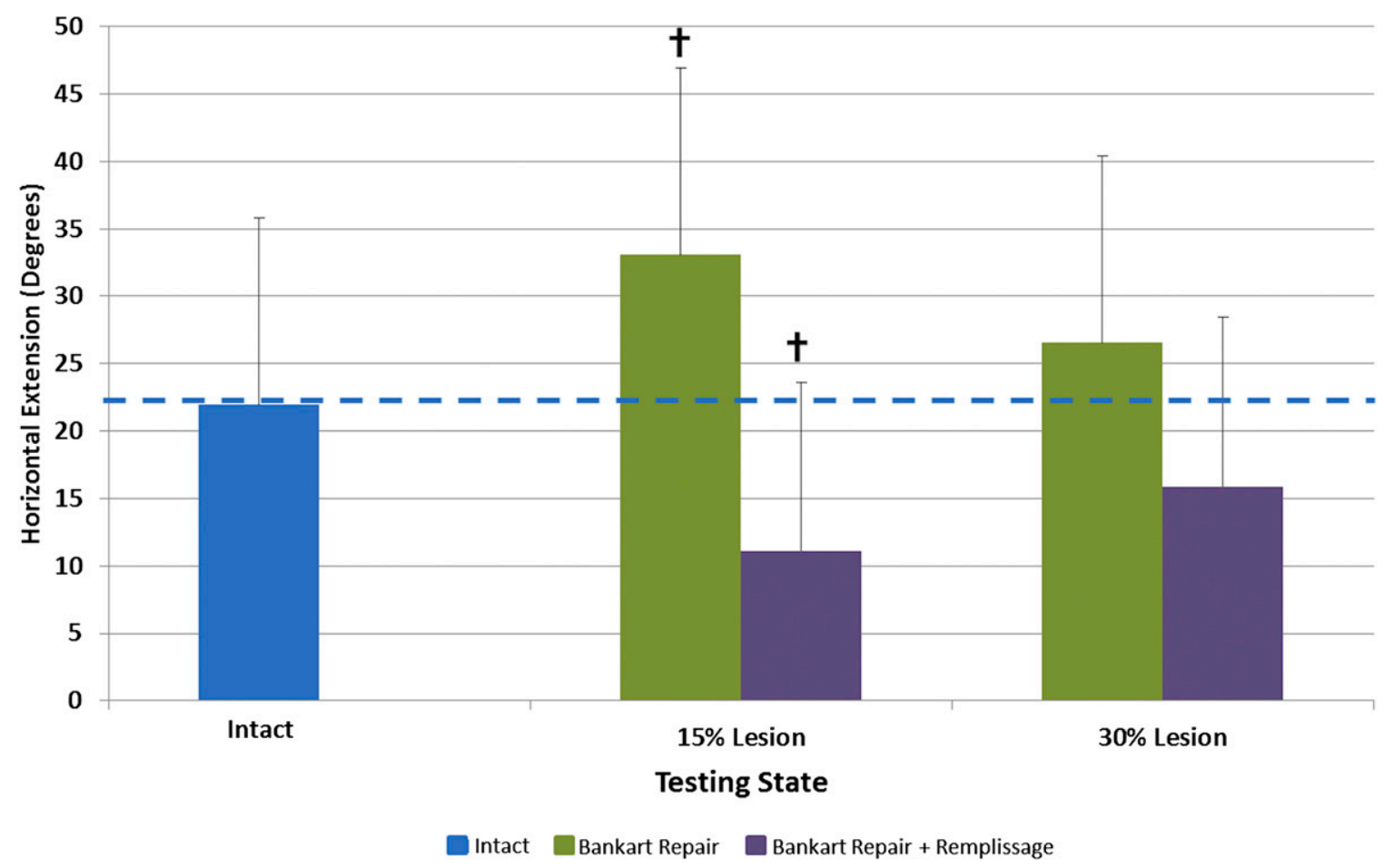

The Effect of the Remplissage Procedure on Shoulder Stability and Range of Motion

Fig. 5-C

Shoulder extension range of motion with the humerus positioned in $90^{\circ}$ of composite abduction and external rotation (the position of anterior apprehension).

and $\mathrm{Kroll}^{33}$ published a case report on restricted external rotation motion after a remplissage procedure. The restricted external rotation motion was believed to be due to the remplissage procedure and was successfully addressed by surgical release of the posterior joint capsule and infraspinatus tenodesis. To our knowledge, no previous biomechanical assessments of the remplissage procedure have been reported.

A validated dynamic shoulder testing apparatus was utilized to replicate the in vivo shoulder ${ }^{22,23}$. This apparatus allowed active muscle loading to reproduce physiologic glenohumeral joint

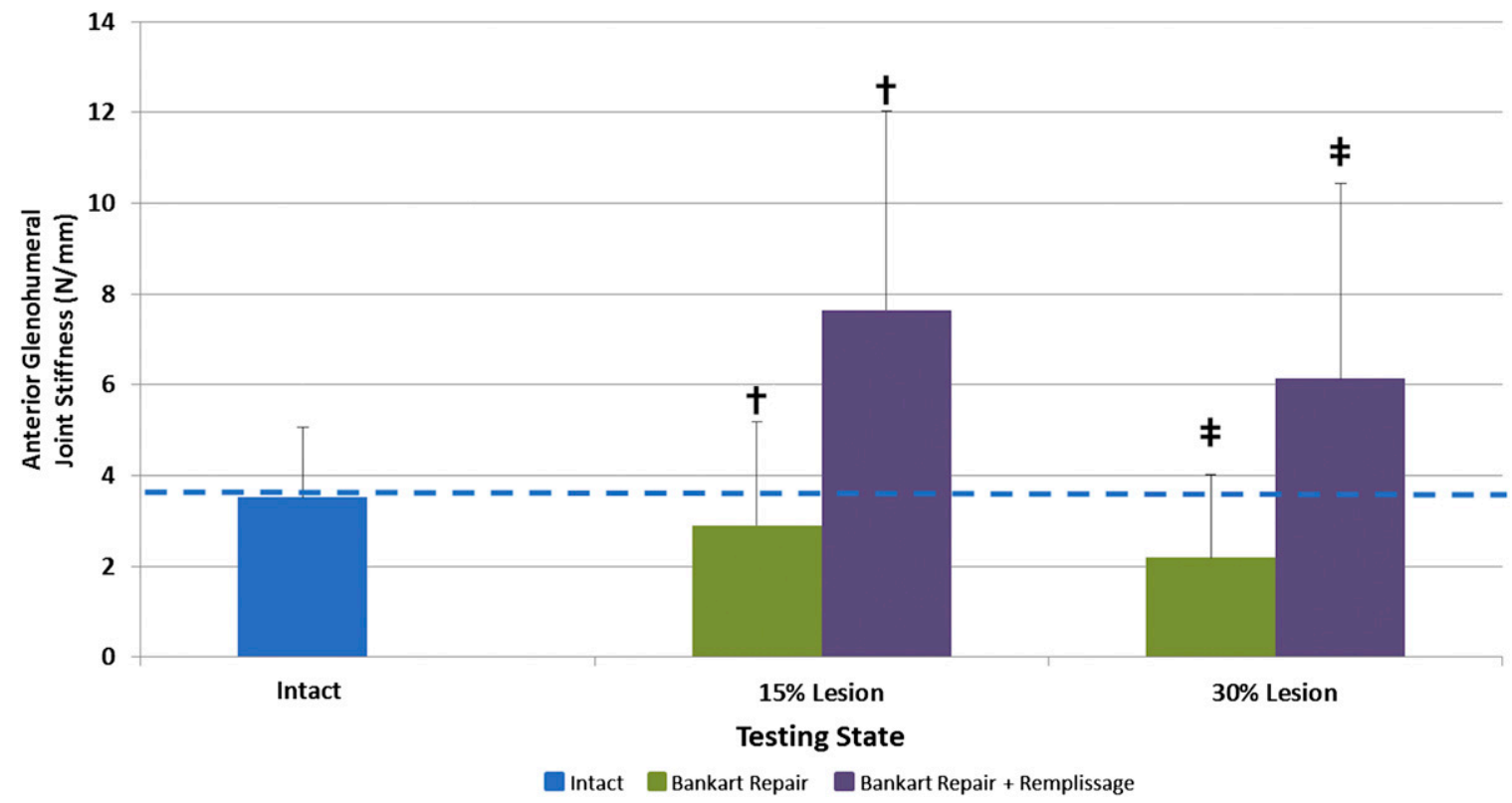

Fig. 6

Glenohumeral joint stiffness determined by applying an external load to the humerus and measuring joint translation. Results are displayed for the intact condition and for $15 \%$ and $30 \%$ Hill-Sachs defects with and without remplissage; $†$ and $\neq$ indicate pairwise comparisons with significant differences. 
The Journal of Bone \& Joint Surgery $\cdot$ Jbjs.org Volume 94-A · Number $11 \cdot$ June 6, 2012
The Effect of the Remplissage Procedure on Shoulder Stability and Range of Motion compression, which was beneficial in assessing joint stability. The testing system also allowed unconstrained physiologic motion, which was not possible in other testing systems used to study Hill-Sachs defects ${ }^{16}$. As the remplissage procedure may be associated with restriction of glenohumeral rotation, we specifically examined internal and external rotation in adduction and abduction. We also wanted to examine the shoulder in the position of apprehension (abduction, external rotation, and extension) to study Hill-Sachs defect engagement and the ability of the Bankart repair with or without remplissage to prevent glenohumeral instability.

A $15 \%$ defect was chosen to represent a small Hill-Sachs defect and a $30 \%$ defect to represent a defect of moderate size $\mathrm{e}^{34}$. The orientation of the Hill-Sachs defects in our specimens was determined according the techniques described by Sekiya et al. ${ }^{16}$ and Yamamoto et al. ${ }^{26}$. Unfortunately, limited biomechanical literature was available to assist in deriving a reproducible method of determining the depth of the experimental Hill-Sachs defects. Therefore, a worst-case scenario was adapted in which the depth of the defect was based on a plane created at the anatomic humeral head-neck junction. Consequently, the results discussed herein are premised on our particular model of the Hill-Sachs defect. It is conceivable that a remplissage procedure performed for a shallower defect may have different results.

In this particular Hill-Sachs defect model, a 15\% defect failed to engage or dislocate after Bankart repair alone. The addition of remplissage to this scenario resulted in significant reductions in glenohumeral joint extension and rotation in adduction compared with the intact condition. Addition of remplissage also resulted in a mean increase in glenohumeral joint stiffness. In these shoulders with a 15\% Hill-Sachs defect, Bankart lesion repair alone was successful in stabilizing the glenohumeral joint; the addition of remplissage provided little benefit.

In contrast, isolated Bankart lesion repair was unable to prevent defect engagement in the shoulders with the 30\% Hill-Sachs defects. Addition of the remplissage procedure was effective in preventing engagement in all specimens, although at the expense of reduced shoulder motion. Significant reduction in rotational motion compared with the intact condition occurred in adduction but not in abduction. For both the $15 \%$ and $30 \%$ defects, remplissage caused significantly greater reduction in rotational motion in adduction than in abduction. The reason for this is unknown, although we theorize that it was due to variations in rotator cuff tension between the two positions. Additionally, we theorized that the remplissage procedure, although it is a capsulodesis, does not result in an inferior capsular shift effect. It thus maintains the volume of the inferior capsular pouch and consequently the rotational motion in abduction.

In one-half of the specimens with $30 \%$ Hill-Sachs defects treated with the remplissage procedure, the posterior softtissue bumper created by the remplissage resulted in impingement against the posterior glenoid rim with posterior pivoting. This occurred during extension in the abducted and externally rotated position and resulted in mild distraction of the glenohumeral joint. This was most likely due to impinge- ment of the remplissage, which prevented normal physiologic rotation of the humeral head.

Remplissage also resulted in a mean increase in glenohumeral joint stiffness, which is a beneficial result when attempting to stabilize an unstable condition. However, the increase in joint stiffness that occurred with the remplissage procedure, and the associated restriction in motion from the capsulodesis effect, can also be grounds for concern. Other procedures that have previously been noted to have this effect, such as the Putti-Platt operation for anterior instability, have been associated with the development of arthritis ${ }^{35-37}$. The largest increase in joint stiffness occurred after remplissage of the $15 \%$ Hill-Sachs defects. This likely occurred because the $15 \%$ Hill-Sachs defects created in this study were sufficiently stabilized with a standard Bankart lesion repair, and the addition of the capsulodesis and tenodesis effects of the remplissage further increased stiffness so that it surpassed the level in the intact condition. Interestingly, the increase in joint stiffness resulting from remplissage in the specimens with a $30 \%$ Hill-Sachs defect brought the joint stiffness value to near normal levels after Bankart lesion repair. This is likely because the isolated Bankart repair was unable to effectively stabilize the $30 \%$ osseous defect.

The limitations of this study include those inherent to most cadaveric biomechanical simulator studies, such as the use of specimens from elderly donors. The results obtained also represent time-zero effects, so it is unknown how these results would change over time in clinical circumstances in which human tissue has the ability to physiologically relax and lengthen. It is likely that some of the motion lost because of the remplissage would return as the reconstruction stretches over time. Additionally, the simulator could not account for joint proprioception, which plays an important role in glenohumeral stability. Similarly, the simulator was unable to replicate the instantaneous physiologic changes in muscle loading that may occur during the process of a traumatic anterior shoulder dislocation. We endeavored to test range-of-motion parameters that have been theorized to be affected by the remplissage procedure, such as internal and external rotation, abduction, adduction, and extension. However, we did not specifically test flexion.

Typically, remplissage is performed arthroscopically, although it can also be done during open surgery ${ }^{38}$. In our experimental protocol, humeral head exposure was required to measure, orient, and create the Hill-Sachs defects. Therefore, our remplissage was performed in an open fashion, through a lesser tuberosity osteotomy. However, we confirmed that the lesser tuberosity osteotomy caused no significant change in any of the parameters tested compared with the intact condition.

The present Hill-Sachs model had clinically relevant defect orientation and width. However, the defect depth, which is believed by some to be a less important factor ${ }^{26}$, represented a worst-case scenario, with the base of the defect corresponding to the humeral head-neck junction. We selected the humeral head-neck junction for reproducibility reasons, as it was relatively easy to identify from specimen to specimen and therefore 
The Journal of Bone \& Joint Surgery $\cdot$ JbjS. org Volume 94-A · Number $11 \cdot$ June 6, 2012
The Effect of the Remplissage Procedure on Shoulder Stability and Range of Motion by other researchers. As such, the results of this study are specific to the particular Hill-Sachs models that were tested and the particular parameters that were studied. Finally, although we reported several statistically significant differences among the tested conditions, we can only suggest that these differences are clinically important. The shoulder simulator itself was one of the strengths of the study because of its sophisticated ability to incorporate osseous and soft-tissue factors that have a bearing on instability.

In summary, this study investigated the biomechanical characteristics of the remplissage procedure for the treatment of Hill-Sachs defects of small and moderate size. In this particular experimental model, a small Hill-Sachs defect (15\%) was adequately addressed with a standard Bankart lesion repair. The addition of remplissage provided little extra benefit and resulted in significant reductions in specific joint motions. However, shoulders with a $30 \%$ Hill-Sachs defect continued to engage and dislocate after isolated Bankart repair. For the defects of moderate size that were modeled in this study, remplissage was effective in preventing engagement and dislocation, although it did so at the expense of specific shoulder motions. The remplissage procedure also increased joint stiffness, a factor of potential concern whose clinical importance is unknown. Further biomechanical studies are needed to more definitively assess the remplissage procedure. Employing advanced techniques such as in vivo kinematic tracking ${ }^{39}$, robotic devices ${ }^{40,41}$ and finite element analy- $\operatorname{sis}^{42}$ may be useful. Specifically, in vivo studies would provide better direct evidence regarding the advantages and adverse effects of surgical procedures. Additionally, further clinical studies are required to determine the indications, adverse effects, and outcomes of the remplissage procedure. The role of the HillSachs defect in shoulder instability also requires further study to determine which attributes (e.g., critical defect width, orientation, and depth) would benefit from surgical intervention.

\section{Appendix}

eA An appendix describing specimen preparation and the shoulder simulator is available with the online version of this article as a data supplement at jbjs.org.

Ilia Elkinson, BHB, MBChB, FRACS

Joshua W. Giles, BESc

Kenneth J. Faber, MD, MHPE, FRCSC

Harm W. Boons, MD

Louis M. Ferreira, BSc, BESc

James A. Johnson, $\mathrm{PhD}$

George S. Athwal, MD, FRCSC

H.U.L.C., St. Joseph's Health Care, 268 Grosvenor Street,

London, ON N6A 4L6, Canada.

E-mail address for G.S. Athwal: gathwal@uwo.ca

\section{References}

1. Hill HA, Sachs MD. The grooved defect of the humeral head. A frequently unrecognized complication of dislocations of the shoulder joint. Radiology. 1940; 35:690-700.

2. Burkhart SS, De Beer JF. Traumatic glenohumeral bone defects and their relationship to failure of arthroscopic Bankart repairs: significance of the inverted-pear glenoid and the humeral engaging Hill-Sachs lesion. Arthroscopy. 2000;16:677-94. 3. Calandra JJ, Baker CL, Uribe J. The incidence of Hill-Sachs lesions in initial anterior shoulder dislocations. Arthroscopy. 1989;5:254-7.

4. Chen AL, Hunt SA, Hawkins RJ, Zuckerman JD. Management of bone loss associated with recurrent anterior glenohumeral instability. Am J Sports Med. 2005;33:912-25.

5. Rowe CR, Zarins B, Ciullo JV. Recurrent anterior dislocation of the shoulder after surgical repair. Apparent causes of failure and treatment. J Bone Joint Surg Am. 1984;66:159-68.

6. Burkhart SS, Danaceau SM. Articular arc length mismatch as a cause of failed bankart repair. Arthroscopy. 2000;16:740-4.

7. Boileau P, Villalba M, Héry JY, Balg F, Ahrens P, Neyton L. Risk factors for recurrence of shoulder instability after arthroscopic Bankart repair. J Bone Joint Surg Am. 2006;88:1755-63.

8. Armitage MS, Faber KJ, Drosdowech DS, Litchfield RB, Athwal GS. Humeral head bone defects: remplissage, allograft, and arthroplasty. Orthop Clin North Am. 2010; 41:417-25.

9. Boone JL, Arciero RA. Management of failed instability surgery: how to get it right the next time. Orthop Clin North Am. 2010;41:367-79.

10. Chapovsky F, Kelly JD 4th. Osteochondral allograft transplantation for treatment of glenohumeral instability. Arthroscopy. 2005;21:1007.

11. Grondin P, Leith J. Case series: Combined large Hill-Sachs and bony Bankart lesions treated by Latarjet and partial humeral head resurfacing: a report of 2 cases. Can J Surg. 2009;52:249-54.

12. Kazel MD, Sekiya JK, Greene JA, Bruker CT. Percutaneous correction (humeroplasty) of humeral head defects (Hill-Sachs) associated with anterior shoulder instability: a cadaveric study. Arthroscopy. 2005;21:1473-8.

13. Kropf EJ, Sekiya JK. Osteoarticular allograft transplantation for large humeral head defects in glenohumeral instability. Arthroscopy. 2007;23:322.e1-5.

14. Moros C, Ahmad CS. Partial humeral head resurfacing and Latarjet coracoid transfer for treatment of recurrent anterior glenohumeral instability. Orthopedics. 2009;32.
15. Re P, Gallo RA, Richmond JC. Transhumeral head plasty for large Hill-Sachs lesions. Arthroscopy. 2006;22:798.e1-4.

16. Sekiya JK, Wickwire AC, Stehle JH, Debski RE. Hill-Sachs defects and repair using osteoarticular allograft transplantation: biomechanical analysis using a joint compression model. Am J Sports Med. 2009;37:2459-66.

17. Tjoumakaris FP, Sekiya JK. Combined glenoid and humeral head allograft reconstruction for recurrent anterior glenohumeral instability. Orthopedics. 2008; 31:497.

18. Weber BG, Simpson LA, Hardegger F. Rotational humeral osteotomy for recurrent anterior dislocation of the shoulder associated with a large Hill-Sachs lesion. J Bone Joint Surg Am. 1984;66:1443-50.

19. Purchase RJ, Wolf EM, Hobgood ER, Pollock ME, Smalley CC. Hill-sachs "remplissage": an arthroscopic solution for the engaging hill-sachs lesion. Arthroscopy. 2008;24:723-6.

20. Koo SS, Burkhart SS, Ochoa E. Arthroscopic double-pulley remplissage technique for engaging Hill-Sachs lesions in anterior shoulder instability repairs. Arthroscopy. 2009;25:1343-8.

21. Wu G, van der Helm FC, Veeger HE, Makhsous M, Van Roy P, Anglin C, Nagels J, Karduna AR, McQuade K, Wang X, Werner FW, Buchholz B; International Society of Biomechanics. ISB recommendation on definitions of joint coordinate systems of various joints for the reporting of human joint motion-part II: shoulder, elbow, wrist and hand. J Biomech. 2005;38:981-92.

22. Kedgley AE, Mackenzie GA, Ferreira LM, Drosdowech DS, King GJ, Faber KJ, Johnson JA. The effect of muscle loading on the kinematics of in vitro glenohumeral abduction. J Biomech. 2007;40:2953-60.

23. Kedgley AE, Mackenzie GA, Ferreira LM, Johnson JA, Faber KJ. In vitro kinematics of the shoulder following rotator cuff injury. Clin Biomech (Bristol, Avon). 2007;22: 1068-73.

24. Giles JW, Boons HW, Ferreira LM, Johnson JA, Athwal GS. The effect of the conjoined tendon of the short head of the biceps and coracobrachialis on shoulder stability and kinematics during in-vitro simulation. J Biomech. 2011: 44:1192-5.

25. Woltring $H$. Data Processing and error analysis. In: Cappozzo A, Berme P, editors. Biomechanics of human movement, applications in rehabilitation, sport and ergonomics. Worthington: Berlec Corporation; 1990. p 203-37.

26. Yamamoto N, Itoi E, Abe H, Minagawa H, Seki N, Shimada Y, Okada K. Contact between the glenoid and the humeral head in abduction, external rotation, and 
1012

The Journal of Bone \& Joint Surgery $\cdot$ Jbjs.org

VOLUME 94-A · Number $11 \cdot$ JunE 6, 2012
The Effect of the Remplissage Procedure on

Shoulder Stability and Range of Motion horizontal extension: a new concept of glenoid track. J Shoulder Elbow Surg. 2007; 16:649-56.

27. Itoi $E$, Lee SB, Berglund LJ, Berge LL, An KN. The effect of a glenoid defect on anteroinferior stability of the shoulder after Bankart repair: a cadaveric study. J Bone Joint Surg Am. 2000;82:35-46.

28. Itoi E, Newman SR, Kuechle DK, Morrey BF, An KN. Dynamic anterior stabilisers of the shoulder with the arm in abduction. J Bone Joint Surg Br. 1994;76: 834-6.

29. McQuade KJ, Murthi AM. Anterior glenohumeral force/translation behavior with and without rotator cuff contraction during clinical stability testing. Clin Biomech (Bristol, Avon). 2004;19:10-5

30. McQuade KJ, Shelley I, Cvitkovic J. Patterns of stiffness during clinical examination of the glenohumeral joint. Clin Biomech (Bristol, Avon). 1999;14:620-7.

31. Wellmann M, Petersen W, Zantop T, Herbort M, Kobbe P, Raschke MJ, Hurschle C. Open shoulder repair of osseous glenoid defects: biomechanical effectiveness of the Latarjet procedure versus a contoured structural bone graft. Am J Sports Med. 2009;37:87-94.

32. Lee TQ, Black AD, Tibone JE, McMahon PJ. Release of the coracoacromial ligament can lead to glenohumeral laxity: a biomechanical study. J Shoulder Elbow Surg. 2001;10:68-72.

33. Deutsch AA, Kroll DG. Decreased range of motion following arthroscopic remplissage. Orthopedics. 2008;31:492.
34. Bollier MJ, Arciero R. Management of glenoid and humeral bone loss. Sports Med Arthrosc. 2010;18:140-8.

35. Green A, Norris TR. Shoulder arthroplasty for advanced glenohumeral arthritis after anterior instability repair. J Shoulder Elbow Surg. 2001;10:539-45.

36. Hawkins RJ, Angelo RL. Glenohumeral osteoarthrosis. A late complication of the Putti-Platt repair. J Bone Joint Surg Am. 1990;72:1193-7.

37. Kiss J, Mersich I, Perlaky GY, Szollas L. The results of the Putti-Platt operation with particular reference to arthritis, pain, and limitation of external rotation.

J Shoulder Elbow Surg. 1998;7:495-500.

38. Abdelhady AM. Neglected anterior shoulder dislocation: open remplissage of the Hill-Sachs lesion with the infraspinatus tendon. Acta Orthop Belg. 2010;76:162-5.

39. Bey MJ, Kline SK, Zauel R, Lock TR, Kolowich PA. Measuring dynamic in-vivo glenohumeral joint kinematics: technique and preliminary results. J Biomech. 2008;41:711-4.

40. Noble LD Jr, Colbrunn RW, Lee DG, van den Bogert AJ, Davis BL. Design and validation of a general purpose robotic testing system for musculoskeletal applications. J Biomech Eng. 2010;132:025001.

41. Woo SL, Debski RE, Wong EK, Yagi M, Tarinelli D. Use of robotic technology for diathrodial joint research. J Sci Med Sport. 1999;2:283-97.

42. Ellis BJ, Drury NJ, Moore SM, McMahon PJ, Weiss JA, Debski RE. Finite element modelling of the glenohumeral capsule can help assess the tested region during a clinical exam. Comput Methods Biomech Biomed Engin. 2010;13:413-8. 